\title{
Congenital complete heart block and persistent ductus arteriosus associated with maternal systemic lupus erythematosus
}

\author{
OLAFUR STEPHENSEN, W P CLELAND, K HALLIDIE-SMITH
}

From the Department of Paediatrics, University Hospital, Reykjavik, Iceland; and the

Cardiovascular Division, Royal Postgraduate Medical School, Hammersmith Hospital, London

SUMMARY A woman with systemic lupus erythematosus had two daughters both of whom had congenital $\stackrel{+}{\circ}$

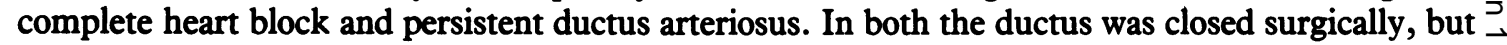
neither required pacing. Two otherwise healthy sons had incomplete right bundle-branch block.

Congenital complete heart block can occur in sibs with and without associated congenital heart defects. ${ }^{1}$ This has been associated with different histological changes, but the ultimate cause has remained obscure. Recently there have been reports of an association between congenital heart block and maternal systemic lupus erythematosus. ${ }^{2-4}$ This report concerns two sisters with congenital complete heart block and persistent ductus arteriosus, whose mother had systemic lupus erythematosus.

\section{Case reports}

\section{MATERNAL HISTORY}

In April 1963 the mother (age 25) developed a maculopapular rash on her extremities. In December 1963 she had a miscarriage in the seventh month of pregnancy. During the following months she had episodes of cloudy vision and blindness and was for the first time found to have an increased sedimentation rate. This remained high for the next 10 years. In May 1967 she gave birth to her older daughter (case 1). During the pregnancy she had exacerbations of her rash. In January 1969 and February 1970 she gave birth to healthy male infants. During these pregnancies she was in unusually good health. Both boys have been healthy, but both have incomplete right bundlebranch block. In September 1973 she gave birth to her younger daughter (case 2). During this pregnancy she was in poor health with the characteristic cutaneous rash of systemic lupus erythematosus, arthralgia, and peripheral oedema. In February
1975 a diagnosis of systemic lupus erythematosus was made. The laboratory findings included positive latex fixation, strongly positive antinuclear antibody, increased $\mathrm{IgG}$ and $\mathrm{IgM}$, and decreased $\mathrm{C}_{4}$ fraction of complement. The clinical and laboratory diag- $\mathbb{\infty}$ nosis was supported by a skin biopsy showing allergic vasculitis. Subsequently she developed pericarditis and pleurisy and was started on systemic corticosteroids. She responded well to treatment and is now in good health.

CASE 1

Born in May 1967. During the last months of the pregnancy the fetal heart rate was found to be slow and heart block was confirmed shortly after birth. She was otherwise a full-term, well-developed infant. Her growth and development have been normal and she has been asymptomatic. When $\frac{D}{O}$ examined at age 9 years she had a heart rate of $60 \fallingdotseq$ per minute and systolic and diastolic murmur typical o of a persistent ductus arteriosus. The electrocardiogram showed complete atrioventricular block with a ventricular rate of 60 per minute. Cardiac catheterisation confirmed the diagnosis of a small persistent ductus arteriosus but disclosed no other cardiac anomalies. Antinuclear antibody and DNA binding were negative. The duct was ligated surgically and the postoperative course was uneventful.

CASE 2

Born in September 1973. Fetal bradycardia was observed before delivery. The presence of a complete atrioventricular block was confirmed shortly after delivery. Heart failure occurred early, with 
very slow weight gain and repeated chest infections during the first year of life. Her motor development was slow and she had severe exertional dyspnoea. At the age of 3 years she had a pulse rate of 46 per minute and physical signs suggesting a large persistent ductus arteriosus and pulmonary hypertension. The electrocardiogram showed complete heart block with a ventricular rate of 46 a minute and biventricular hypertrophy. Antinuclear antibody and DNA binding were negative. Cardiac catheterisation disclosed the following: right ventricular pressure $110 / 10$, pulmonary artery pressure $110 / 70$, descending aorta $110 / 70 \mathrm{mmHg}$. The catheter passed readily through the persistent ductus arteriosus; there was no shunt in either direction through the duct; the pulmonary arteriolar resistance was raised to 29 units. Brachial and femoral artery oxygen saturation were 97 and 95 per cent, respectively. A large duct was ligated, with a $10 \mathrm{~mm}$ fall in pulmonary artery pressure and a $10 \mathrm{~mm}$ rise in aortic pressure. The postoperative course was uneventful.

When seen two and a half years after her operation her condition was much improved. The height and weight were in the 25th to 50th centile (that is normal for her age). She had a grade $2 / 6$ systolic murmur at the left sternal edge but no diastolic murmur. Her heart is still enlarged and the electrocardiogram shows biventricular hypertrophy. Cardiac catheterisation disclosed a pulmonary artery pressure of $44 / 16 \mathrm{mmHg}$ with a systemic pressure of $105 / 70 \mathrm{mmHg}$. Her pulse rate was 48 per minute, rising to 60 per minute on exertion.

\section{Discussion}

Infants of mothers with systemic lupus erythematosus occasionally have transient manifestations of the disease, ${ }^{5}$ mainly discoid rashes and haematological abnormalities. These manifestations tend to disappear in the early months of life. It has been suggested that they are caused by immune complexes formed in response to pathological IgG antibody from the mother passing along the placenta to the fetus. ${ }^{6}$ The presence of antinuclear antibody in the circulation of infants with neonatal lupus erythematosus, ${ }^{7}$ has given support to this theory, Other additional factors are needed, however, to produce signs of disease in the infant, as antinuclear antibody has also been found in asymptomatic infants of mothers with systemic lupus erythematosus. Systemic lupus erythematosus involves the heart in over 50 per cent of patients. ${ }^{8}$ The most frequent cardiac manifestations are pericarditis and myocarditis, but various conduction disturbances have also been reported. ${ }^{\circ}$ Complete atrioventricular block has been known to occur but reports have been few. ${ }^{8-11}$ At necropsy the cardiac conduction system of patients with systemic lupus erythematosus and complete heart block has disclosed replacement of the atrioventricular and sinuatrial nodes with granulation tissue and degenerative changes. ${ }^{910}$ Similar histopathological changes have been found in infants with complete congenital block born to mothers with systemic lupus erythematosus. ${ }^{412}$ Chameides et al. ${ }^{4}$ have suggested that this could either be the result of an injury during a critical period in cardiac development or destruction and fibrosis of the fully developed atrioventricular node by active inflammation.

McCue et al. ${ }^{2}$ were the first to draw attention to the relation between maternal systemic lupus erythematosus and complete congenital block though occasional case reports had been published. In reviewing 22 children seen in their clinic with complete congenital heart block, McCue et al. ${ }^{2}$ found clinical or laboratory evidence of systemic lupus erythematosus in 11 out of 19 mothers. Four of the mothers had only laboratory evidence of the disease. Though the diagnosis of systemic lupus erythematosus was made as late as 1975, the mother in our report probably had her first symptoms in April 1963. This was followed by a spontaneous abortion in December 1963. Mund et al. ${ }^{13}$ described increased abortion rates in patients with systemic lupus erythematosus, not only after but also before the clinical appearance of the disease.

Systemic lupus erythematosus is subject to great fluctuations. Symptoms are known to increase during pregnancy ${ }^{14}$ : the mother in this report experienced exacerbations during three of five pregnancies. One of these terminated in a spontaneous abortion and two resulted in the birth of daughters with congenital heart block and persistent ductus arteriosus. The fact that her health was unusually good while carrying her two healthy sons might suggest that a certain quantity or type of material antobody is needed at a specific vulnerable period in cardiac development, both to bring about the symptoms of the disease in the mother and to disrupt the conduction system in the fetus.

Congenital heart block is the only conduction disturbance so far described in association with maternal systemic lupus erythematosus. The two healthy sons of this mother have incomplete right bundle-branch block with QRS complexes of $0.1 \mathrm{~s}$ duration at age 8 and 10 years, respectively. Whether this has any connection with the maternal disease is uncertain. Esscher and Scott ${ }^{6}$ reviewing the published reports and reporting their own cases suggest that maternal systemic lupus erythematosus and other connective tissue diseases are of major 
importance in the aetiology of congenital heart block. Associated defects are seen in 15 to 20 per cent of these patients. ${ }^{6} 15$ Different types of defects have been described. Persistent ductus arteriosus has previously been reported in four infants with congenital heart block of mothers with systemic lupus erythematosus. ${ }^{2}{ }^{6}$ Further studies are clearly needed to define the maternal antibody and the fetal factors needed to produce congenital heart block. With the high incidence of concomitant heart defects, this might also increase our knowledge of the aetiology of congenital heart defects as a whole.

\section{References}

1 Michaelsson M, Engle MA. Congenital complete heart block: an international study of the natural history. Cardiovasc Clin 1972; 4: 85-101.

2 McCue CM, Mantakas ME, Tingelstad JB, Ruddy S. Congenital heart block in newborns of mothers with connective tissue disease. Circulation 1977; 56: 82-90.

3 Winkler RB, Nora AH, Nora JJ. Familial congenital complete heart block and maternal systemic lupus erythematosis. Circulation 1977; 56: 1103-7.

4 Chameides L, Truex RC, Vetter V, Rashkind WJ, Galioto FM Jr, Noonan JA. Association of maternal systemic lupus erhythematosus with congenital complete heart block. $N$ Engl f Med 1977; 297: 1204-7.

5 Vonderheid EC, Koblenzer PJ, Ming PLM, Burgoon CF Jr. Neonatal lupus erythematosus. Report of four cases with review of the literature. Arch Dermatol 1976; 112: 698-705.

6 Esscher E, Scott JS. Congenital heart block and maternal systemic lupus erythematosus. $\mathrm{Br} \mathrm{Med} \mathcal{f}$ $1979 ;$ i: $1235-8$.
7 Beck JS, Rowell NR. Transplacental passage of antinuclear antibody. Lancet 1963; i: 134-5.

8 Moffitt GR Jr. Complete atrioventricular dissociation $\overrightarrow{\bar{B}}$ with Stokes-Adams attacks due to disseminated lupus erythematosus. Ann Intern Med 1965; 63: 508-11.

9 James TN, Rupe CE, Monto RW. Pathology of the $\frac{\widehat{D}}{\vec{D}}$ cardiac conduction system in systemic lupus $\_$ erythematosus. Ann Intern Med 1965; 63: 402-10. के

10 Bharati S, de la Fuente DJ, Kallen RJ, Freij Y, Lev $M$. Conduction system in systemic lupus erythematosus with atrioventricular block. $\mathrm{Am} \mathcal{f}$ Cardiol 1975; 35: 299-304.

11 Wray $R$, Iveson $M$. Complete heart block and systemic lupus erythematosus. Br Heart $f$ 1975; 37: 982-3.

12 Hull D, Binns BAO, Joyce D. Congenital heart $\overrightarrow{.}$ block and widespread fibrosis due to maternal lupus $\vec{D}$ erythematosus. Arch Dis Child 1966; 41: 688-90.

13 Mund A, Simson J, Rothfield N. Effect of pregnancy on course of systemic lupus erythematosus. $\mathfrak{F} A M A$ 1963; 183: 917-20.

14 Dubois EL. Lupus erythematosus. 2nd ed. Los Angeles: University of Southern California Press, 1974: 347.

15 Hardy JD, Solomon S, Banwell GS, Beach R, Wright V, Howard FM. Congenital complete heart block in the newborn associated with maternal systemic lupus erythematosus and other connective tissue disorders. Arch Dis Child 1979; 54: 7-13.

Requests for reprints to W P Cleland, Esq., FRCS, Department of Surgery, Cardiothoracic Institute, Brompton Hospital, Fulham Road, London SW3 6HP. 